\title{
PENENTUAN STRATEGI BAURAN PEMASARAN PELUMAS FOOD GRADE GREASE BERBAHAN DASAR KELAPA SAWIT DI KABUPATEN PURBALINGGA
}

\author{
Tri Yanto dan Anis Aiman Abulkhair \\ Jurusan Teknologi Pertanian Universitas Jenderal Soedirman \\ E-mail : triyantosuwarjo@yahoo.co.id
}

\begin{abstract}
The objective of this study is to determine the merchant and the user preferences to the specification lubricating grease lubricants, color lubricants, package sizes, shape packaging labels, distribution of lubricants, promotion, and price. Sampling using purposive sampling technique. Analysis of data using friedman test with 5\% error level. If there are differences then tested further by LSD. The results of this research note that lubricant specifications preferred by merchants, which is preferred by the user while the grease is food grade lubricants and general machinery lubrication; the color lubricant preferred by merchantsis natural and blue, which is preferred by the user while the grease is the natural color; pack sizes preferred by merchants is size $350 \mathrm{~g}$ and $150 \mathrm{~g}$ with packing cup and bulk, while users liked the size of $350 \mathrm{~g}$ with packing cup; form label lubricants are preferred by merchants grease a round shape that is labeled with red and green as well as a square shape label in red, while the grease is preferred by the user labels round and square shapes in red; lubricants distribution are preferred by merchants grease ie grocery stores, retail stores, repair shops, and peddlers, while the grease is preferred by the user distribution through grocery stores and workshops; lubricants promotion are preferred by merchants grease is through internet media, banners, brochures, radio and posters, while users of grease liked by media promotion banners, brochures and posters; the price lubricant grease favored by merchants as preferred by the user of grease that low price low quality, medium quality and medium price high price of high quality.
\end{abstract}

Keywords: new products, food grade grease, marketing

Abstrak: Tujuan penelitian untuk mengetahui kesukaan pedagang dan pengguna
pelumas grease terhadap spesifikasi pelumas, warna pelumas, ukuran kemasan, bentuk
label kemasan, distribusi pelumas, promosi pelumas, dan harga. Pengambilan sampel
menggunakan teknik purposive sampling. Analisis data menggunakan uji friedman
dengan taraf kesalahan 5\%. Jika terdapat perbedaan maka diuji lanjut dengan LSD
rank. Hasil penelitian ini diketahui bahwa spesifikasi pelumas yang disukai oleh
pedagang, yaitu pelumas spesifikasi food grade, sedangkan yang disukai oleh
pengguna grease yaitu pelumas food grade dan pelumas mesin umum; Warna pelumas
yang disukai oleh pedagang yaitu warna natural dan warna biru, sedangkan yang
disukai oleh pengguna yaitu warna natural; ukuran kemasan yang disukai oleh
pedagang yaitu ukuran $350 \mathrm{~g}$ dan $150 \mathrm{~g}$ dengan kemasan cup dan curah, sedangkan
pengguna menyukai ukuran $350 \mathrm{~g}$ dengan kemasan cup; bentuk label pelumas yang
disukai oleh pedagang yaitu label bentuk bulat dengan warna merah dan hijau serta
label bentuk persegi dengan warna merah, sedangkan yang disukai oleh pengguna
yaitu label bentuk bulat dan persegi dengan warna merah; distribusi pelumas yang
disukai oleh pedagang yaitu toko grosir, toko eceran, bengkel dan pedagang keliling,
sedangkan yang disukai oleh pengguna yaitu distribusi melalui toko grosir dan
bengkel; promosi pelumas yang disukai oleh pedagang yaitu melalui media internet, 
spanduk, brosur, radio dan poster, sedangkan pengguna menyukai promosi melalaui media spanduk, brosur dan poster; harga pelumas yang disukai oleh pedagang sama seperti yang disukai oleh pengguna yaitu harga rendah mutu rendah, harga menengah mutu menengah, dan harga tinggi mutu tinggi.

Kata Kunci: produk baru, food grade grease, pemasaran

\section{PENDAHULUAN}

Perkebunan kelapa sawit Indonesia mengalami pertumbuhan yang sangat pesat. Indonesia diperkirakan akan menjadi produsen minyak sawit terbesar di dunia dengan laju pertumbuhan produksi $2,50 \%$ pada tahun 2011 dengan total produksi CPO sebesar 22,55 juta ton/tahun (Dirjen Perkebunan, 2012).Pada tahun 2013 diperkirakan produksi CPO mencapai 30 juta ton (Dewan Minyak Sawit Indonesia, 2013). Padahal sejak pertengahan tahun 1999 harga minyak sawit berfluktuasi sangat tajam. Oleh karena itu perlu diantisipasi pemanfaatan minyak sawit dengan melakukan diversifikasi produk hilirnya. Salah satu alternatif yang sangat potensial ialah menjadikan produk minyak sawit sebagai bahan dasar pembuatan pelumas grease khusus untuk kebutuhan industri pangan termasuk juga untuk industri pakan ternak, farmasi dan kosmetik (food grade grease).

Pelumas foodgrade grease sangat dibutuhkan industri pangan untuk menjamin keamanan pangan yang produk, sebagaimana bahaya penggunaan pelumas non-food grade grease jika mengkontaminasi hasil olahan pangan dan dikonsumsi manusia adalah terjadinya penimbunan bahan anorganik khususnya logam berat. Logam berat yang tertimbun di tubuh dapat mengakibatkan keracunan pada konsumen yang berdampak pada kesehatan (Kupcinskas et al., 2012).

Oleh karena itu, peluang kebutuhan pelumas grease khusus (food grade grease) untuk industri pangan, pakan ternak, farmasi dan kosmetik dimasa mendatang akan semakin meningkat. Potensi peningkatan kebutuhan pelumas grease tersebut tentunya perlu diantisipasi dengan memproduksi pelumas grease khusus untuk kebutuhan industri pangan, pakan ternak farmasi dan kosmetika.

Penelitian Tri Yanto et al.( 2009a) memberikan informasi uji kinerja food grade grease minyak sawit memiliki nilai droppingpoint $190,5^{\circ} \mathrm{C}$, penetrasi unworked pada skala 256,9(NLGI 3-2) dan worked pada skala 280,2 (NLGI 2), daya tahan korosi golongan 1a, wheelbearing dengan nilai kebocoran 25,56 g, weldingpoint dalam 200 Kgf, dan wear scar $0,886 \mathrm{~mm}$. Grease komersial memiliki nilai droppingpoint $135,15^{\circ} \mathrm{C}$, penetrasi skala 224,13 (NLGI 3) pada unworked dan worked skala 235,1 (NLGI 3), wheel bearing dengan nilai kebocoran 38,98 $\mathrm{g}$, welding point dalam $200 \mathrm{Kgf}$, dan grease komersial memiliki panjang goresan lebih tinggi. Secara umum food grade grease minyak sawit memiliki kinerja yang jauh lebih baik dibandingkan grease komersial yang diteliti. Food grade greaseminyak sawitjuga lebih disukai dibandingkan dengan grease komersial.

Food grade grease merupakan produk pelumas baru yang belum diketahui oleh penjual pelumas dan pengusaha jasa mesin pengolahan pangan di Kabupaten Purbalingga sehingga diperlukan penentuan strategi bauran pemasaran produk baru food grade grease untuk menunjang keberhasilan produksi pelumas food grade grease. Tujuan umum penelitian ini adalah untuk menentukan strategi pemasaran food grade grease yang meliputi kebijakan produk, harga, distribusi dan promosi. Adapun tujuan khusus penelitian ini yaitu untuk mengetahui kesukaan pedagang dan pengguna pelumas grease terhadap spesifikasi pelumas, warna pelumas food grade grease, ukuran kemasan pelumas food grade grease, bentuk label kemasan pelumas food grade grease, distribusi pelumas food grade grease, promosi pelumas food grade grease dan harga pelumas food grade grease.

\section{METODE PENELITIAN}

Penelitian ini merupakan penelitian survei untuk menentukan kebijakan strategi pemasaran food grade grease berbahan dasar minyak sawit. Lokasi Penelitian ini dilaksanakan di Kabupaten Purbalingga.Waktu penelitian dari Bulan April sampai Oktober 2014. 
Data yang digunakan dalam penelitian ini terdiri atas data primer dan data sekunder. Pengumpulan data primer dilaksanakan secara langsung dengan alat kuesioner melalui wawancara dan observasi langsung, sedangkan data sekunder diperoleh dari studi pustaka.

Variabel yang diamati dalam penelitian ini meliputi: kesukaan spesifikasi pelumas, kesukaan warna pelumas food grade grease, kesukaan ukuran dan jenis kemasan pelumas food grade grease, kesukaan bentuk label kemasan pelumas food grade grease, kesukaan distribusi pelumas food grade grease, kesukaan promosi pelumas food grade greasdan kesukaan harga food grade grease.

Pengambilan sampel menggunakan teknik purposive sampling. Dipilih IKM pengolahan pangan yaitu pengusaha penggilingan bumbu, daging dan kelapa yang berada di pasar di Kabupaten Banyumas. Pemilihan IKM tersebut didasarkan pertimbangan bahwa konsumen pengusaha penggililingan bumbu, daging dan kelapa adalah ibu rumah tangga dan pedagang warung makan, dimana mereka setiap hari memasak menggunakan bumbu yang digiling di pasar sehingga resiko untuk terkontaminasi pelumas non food grade sangat besar.Selain pengusaha penggilingan bumbu, daging dan kelapa juga diambil sampel untuk toko penjual pelumas untuk mengetahui jenis pelumas yang laku dipasar. Secara purposive dipilih 3 pasar tempat usaha para pengusaha penggilingan, yaitu Pasar Segamas, Pasar Bobotsari dan Pasar Bukateja. Dari 3 pasar tersebut diperoleh 30 pengusaha penggilingan bumbu, daging dan kelapa. Responden penjual pelumas grease sebanyak 5 toko teknik di sekitar Kota Purbalingga.

Analisis data yang digunakan adalah uji Friedman dengan tingkat kesalahan 5\%. Jika ada perbedaan kesukaan, dilakukan uji lanjut dengan uji LSD (Least Significance Different) untuk mengetahui yang paling disukai.

\section{HASIL DAN PEMBAHASAN}

Strategi pemasaran sangat penting dan dibutuhkan untuk memasarkan produk yang dihasilkan oleh perusahaan, terutama untuk memasarkan produk baru yang belum dikenal oleh calon konsumen. Salah satu penyebab kegagalan pengembangan produk baru adalah strategi bauran pemasaran yang tidak tepat (Moore dan Pessemier, 1993).

Food grade grease sebagai produk pelumas baru yang memiliki spesifikasi yang sesuai untuk alat dan mesin pengolahan pangan memerlukan konsep bauran pemasaran yang tepat. Agar suatu strategi dapat berhasil diterapkan dan tepat sasaran, maka strategi tersebut harus dilaksanakan pada saat yang tepat dan dengan cara yang tepat.

\section{Kesukaan Spesifikasi pelumas}

Berdasarkan Gambar 1(a) diketahui bahwa tingkat kesukaan spesifikasi pelumas oleh pengguna grease cenderung menyukai semua spesifikasi pleumas baik food grade maupun pelumas mesin umum. Sedangkan Gambar 2(b).kesukaan spesifikasi pelumas pedagang grease yang paling disukai oleh pedagang yaitu pelumas mesin umum. Pengguna lebih menyukai menggunakan pelumas gresase mesin umum dan food grade dikarenakan pengguna hanya mengetahui pelumas mesin biasa, akan tetapi setelah diperkenalkan dengan pelumas grease food grade mereka menjadi tertarik karena fungsi food grade grease yang aman digunakan untuk mesin pengolahan. Belum beredarnya pelumas food grade grease dipasaran menyebabkan pegguna lebih memilih menggunakan pelumas grease mesin umum. Selain itu, pelumas grease mesin umum kualitasnya sudah terbukti bagus dan terjamin kuaitasnya, dan sudah banyak digunakan pengguna untuk melumasi mesin-mesin pengolahan pangan mereka. Ketidaktauan konsumen terhadap food greade grease dikarenakan tidak adanya grease yang berspesifikasi food grade yang beredar di pasaran terutama di wilayah Kabupaten Purbalingga. Konsumen yang tidak mengetahui informasi produk food grade grease tidak akan mencari produk tersebut apalagi membeli produk. Sedangkan penjual grease lebih menyukai pelumas food grade grease, karena mereka tahu pelumas grease mesin umum tidak baik digunakan untuk mesin-mesin pengolahan pangan, apa lagi jika mengkontaminasi bahan pangan yang diolahnya, namun dikarenakan pelumas food grade grease belum ada dipasaran, mereka tetap menjual pelumas grease mesin umum kepada pengguna mesinmesin pengolahan pangan. 


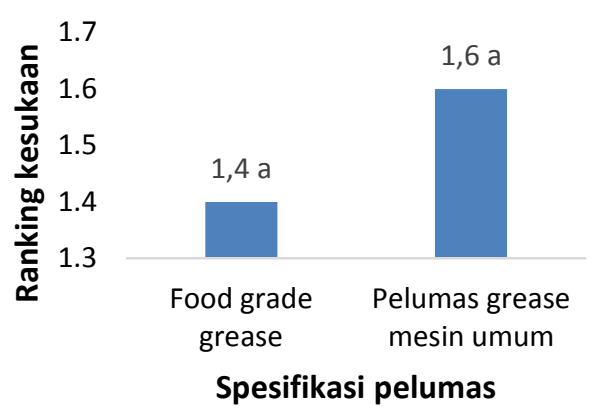

(a)

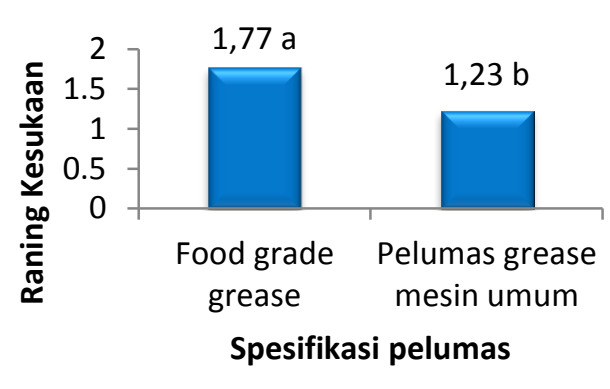

(b)

Keterangan: (a) ranking kesukaan spesifikasi pelumas grease oleh pengguna

(b) ranking kesukaan spesifikasi pelumas grease oleh pedagang

Gambar 1. Kesukaan spesifikasi pelumas food grade grease

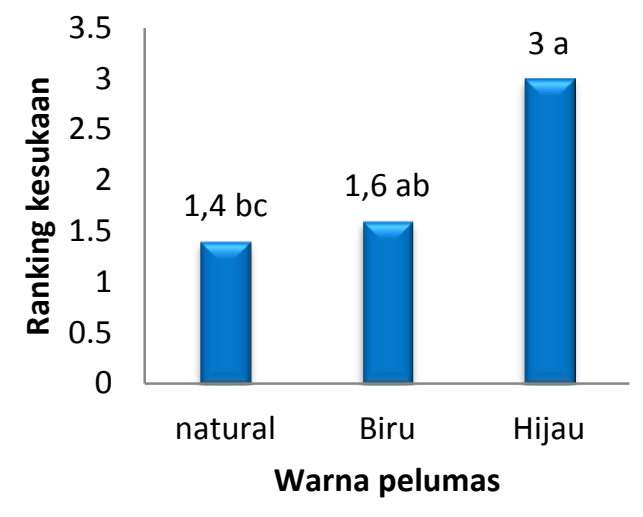

(a)

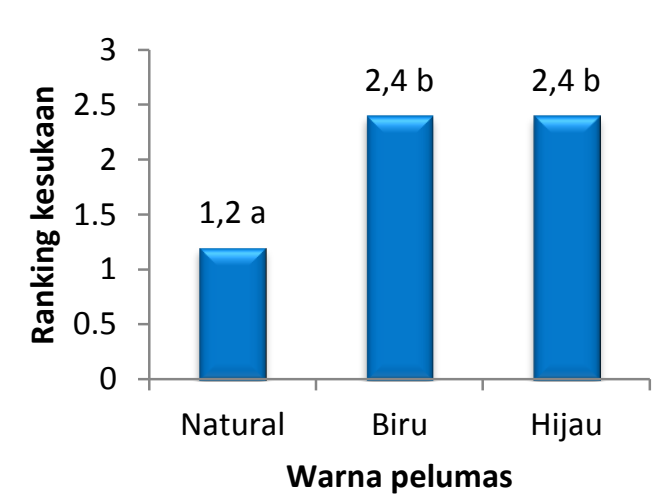

(b)

Keterangan: (a) ranking kesukaan warna pelumas grease oleh pedagang pelumas

(b) ranking kesukaan warna pelumas grease oleh pengguna pelumas

Gambar 2. Kesukaan warna food grade grease

\section{Kesukaan warna pelumas food grade grease}

Berdasarkan Gambar 2 diketahui bahwa tingkat kesukaan pengguna grease terhadap warna pelumas yaitu menyukai pelumas food grade grease berwarna natural kuning, sedangkan untuk pedagang warna pelumas yang food grade grease yang disukai adalah warna narutal kuning dan warna biru. Warna natural kuning lebih disukai karena warna tersebut tidak akan mengkontaminasi bahan pangan. Warna food grade grease natural hampir menyerupai dengan warna bahan pangan yang biasanya diolah menggunakan mesin pengolahan pangan. Konsumen mengkawatirkan jika pelumas kontak dengan produk hasil olahan pangan dikawatirkan warna dari pelumas akan mempengaruhi hasil olahan pangan sehingga mampu menurunkan kualitas hasil olahan. Adanya kekawatiran tersebut harus direspon oleh produsen, sebagaimana spesifakasi produk food grade yang khusus digunakan pada alat dan mesin pengolahan pangan maka grease food grade harus menggunakan pewarna alami atau pewarna nonsistetis. Sementara warna biru dan hijau kurang disukai oleh responden baik kalangan pengguna maupun pedagang, karena mereka beranggapan warna tersebut akan mengkontaminasi bahan pangan ketika pelumas tersebut digunakan.

Kesukaan terhadap warna juga dipengaruhi oleh psikologis dari konsumen. 
Sehingga dibutuhkan warna dan juga bahan pewarna pelumas yang tepat untuk strategi pemasaran produk baru pelumas food grade grease. Warna adalah salah satu dari dua unsur yang menghasilkan daya tarik visual, dan kenyataannya warna lebih berdaya tarik pada emosi daripada akal. Orang menyenangi warna dan mereka bereaksi di bawah sadar terhadap warna; suatu pembawaan menyenangi warna merupakan bagian dari kejiwaan manusia. Warna membantu mengurangi hambatan penjualan. Warna mencapai targetnya melalui respon fisiologis, respon psikologis, daya tarik pada indera, daya tarik pada emosi (Natadjaja, 2002).

\section{Kesukaan ukuran kemasan pelumas food grade grease}

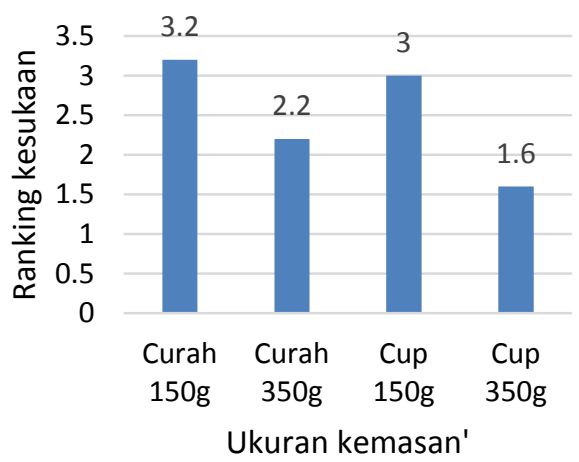

(a)
Berdasarkan Gambar 3 tingkat kesukaan kemasan food grade grease cenderung bervariasi, mereka suka semua jenis dan ukuran kemasan karena semakin banyak pilihan yang ada maka semakin banyak barang yang ditawarkan sehingga mereka mendapatkan keuntungan yang besar. Sedangkan ukuran kemasan 350 g menjadi ukuran kemasan yang paling disukai oleh pengguna pelumas grease, hal ini dikarenakan kemasan tersebut dianggap paling praktis dibandingkan dengan kemasan lainya. Kemasan cup $350 \mathrm{~g}$ punya kemudahan untuk dibuka dan ditutup sehingga paling disukai oleh konsumen. Kemasan cup $350 \mathrm{~g}$ juga memiliki desain kemasan yang cukup kokoh dan cukup aman ketika dilakukan penyimpanan.

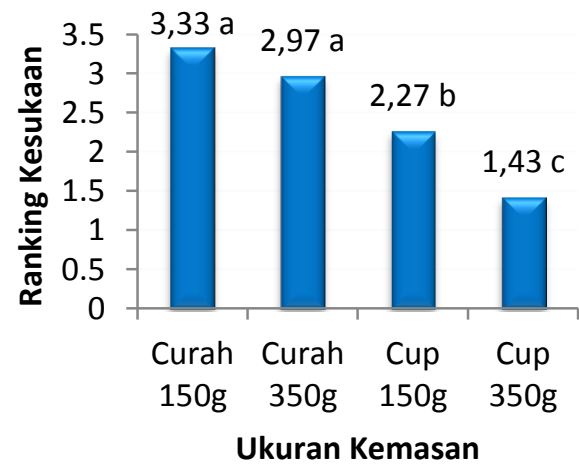

(b)

Keterangan: (a) ranking kesukaan ukuran kemasan pelumas grease oleh pedagang pelumas (b) ranking kesukaan ukuran kemasan pelumas grease oleh pengguna pelumas

Gambar 3. Kesukaan ukuran kemasan food grade grease

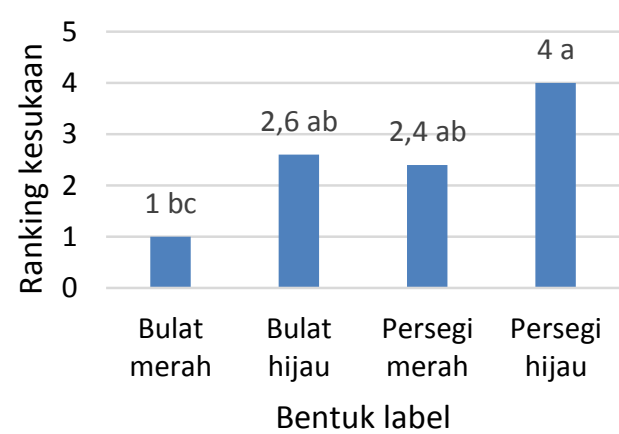

(a)

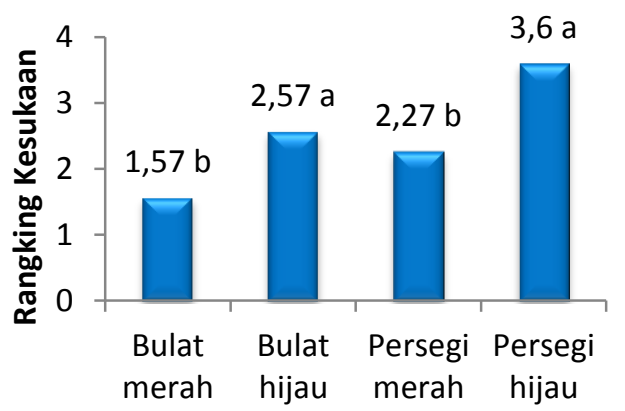

Bentuk label

(b)

Keterangan: (a) ranking kesukaan bentuk label pelumas grease oleh pedagang pelumas

(b) ranking kesukaan bentuk label pelumas grease oleh pengguna pelumas

Gambar 4. Kesukaan bentuk label kemasan food grade grease 


\section{Kesukaan bentuk label pelumas food grade grease}

Berdasarkan Gambar 4 bentuk label kemasan yang disukai oleh pedagang yaitu bulat merah, bulat hijau dan persegi merah, sedangkan pengguna lebih menyukai bentuk label bulat merah dab persegi merah. Label bulat merah dianggap label yang mempunyai gambar desain paling menarik bila dibandingkan dengan label persegi hijau. Peran Label pada suatu produk sangat penting untuk memperoleh produk yang sesuai dengan yang diinginkan konsumen. Label produk yang dijamin kebenarannya akan memudahkan konsumen dalam menentukan beragam produk dan subtitusi di pasaran serta label juga dapat memberikan nilai tambah bagi produk (Engel et al., 1995).

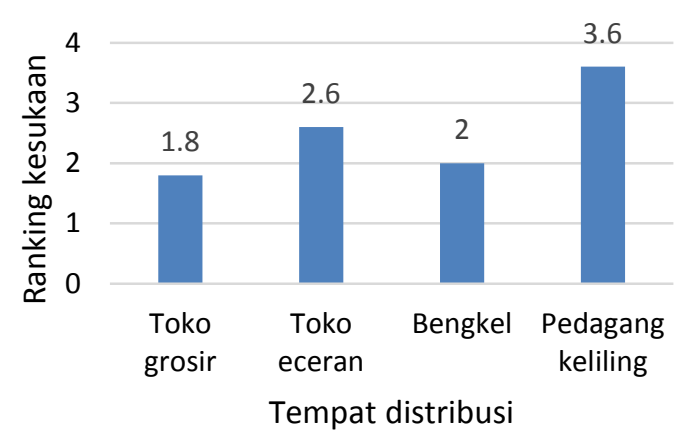

(a)
5. Distribusi pelumas food grade grease Berdasarkan Gambar 5.pedagang pelumas grease menyukai semua aternatif saluran distribusi baik itu toko grosir, toko eceran, bengkel dan pedagang keliling. Sedangkan pengguna grease menyukai distribusi food grade grease melalui toko grosir dan bengkel. Salah satu faktor kesuksesan distribusi adalah kecepatan distribusi, kecepatan distribusi menjadi kunci kepuasan konsumen sehingga konsumen diharapkan loyal terhadap produk pelumas food grade grease.Hal ini sesuai dengan pendapat Tjiptono (2002), bahwa distribusi bertujuan untuk mempermudah konsumen mendapatkan produk yang diinginkan. Adanya toko grosir dan bengkel yang dekat dengan konsumen menjadi lokasi yang strategis untuk memasarkan produk.

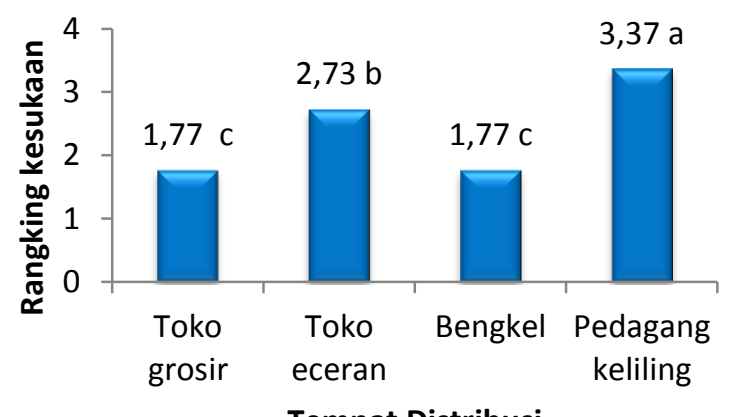

(b)

Keterangan: (a) ranking kesukaan distribusi pelumas grease oleh pedagang pelumas

(b) ranking kesukaan distribusi label pelumas grease oleh pengguna pelumas

Gambar 5. Kesukaan distribusi food grade grease

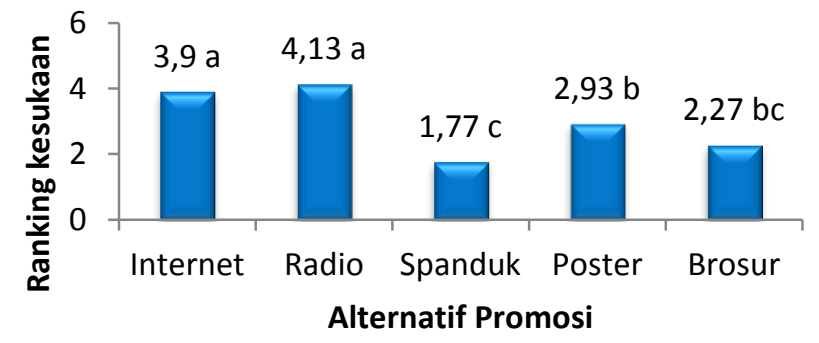

(a)

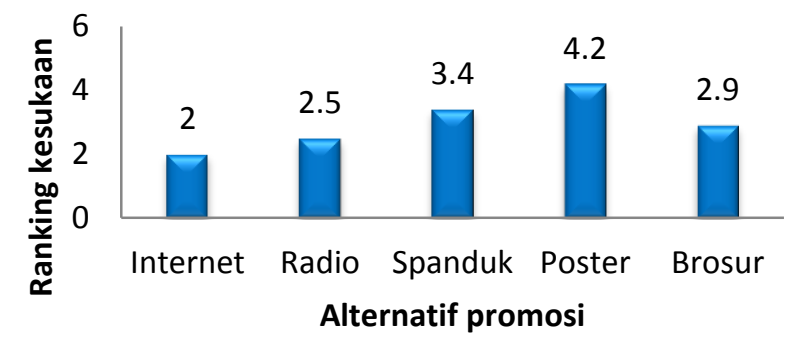

(b)

Keterangan: (a) ranking kesukaan promosi pelumas grease oleh pengguna pelumas

(b) ranking kesukaan promosi pelumas grease oleh pedagang pelumas

Gambar 6. Kesukaan promosi food grade grease 


\section{Kesukaan promosi pelumas food grade grease}

Berdasarkan Gambar 6. diketahui bahwa kesukaan pengguna grease terhadap promosi pelumas food grade grease yang disukai yaitu promosi lewat spanduk dan brosur. Spanduk dan brosur disukai karena pengguna mendapatkan informasi secara detail dan mudah, mereka dapat melihat spanduk iklan di jalan utama yang sering dilalui serta memiliki brosur produk yang bias disimpan di kantor atau toko sehingga sewaktu-waktu membutuhkan informasi pelumas food grade grease dapat langsung diperoleh dengan cepat. Sedangkan penjual grease menyukai semua media promosi baik melalui internet, radio, brosur, spanduk dan poster. Hal ini karena semakin banyak media promosi yang digunakan akan membantu produk diketahui calon pembeli sehingga dapat cepat terjual.

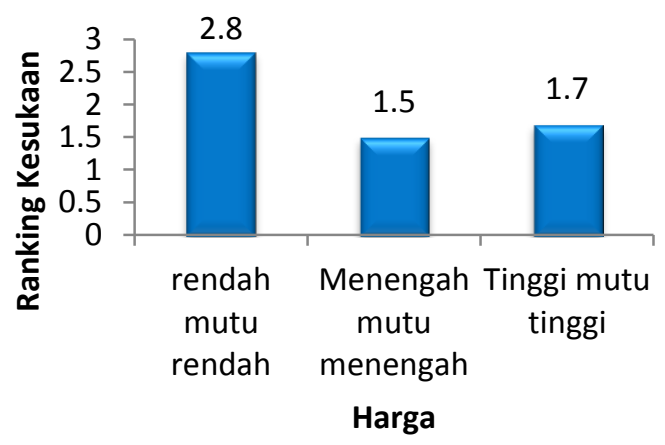

(a)

\section{Kesukaan harga pelumas food grade grease}

Berdasarkan Gambar 7 diketahui bahwa baik pedagang maupun pengguna grease cenderung menyukai semua alternatif harga yang ditawarkan yaitu harga rendah mutu rendah, harga menengah mutu menengah dan harga tinggi mutu tinggi. Kesukaan ini dikarenakan semua pilihan harga yang ditawarkan secara prinsip sama yaitu harga sesuai dengan mutu.

Pelumas food grade grease agar mampu bersaing dengan produk pelumas lain yang telah mapan di pasaran harus mampu bersaing dalam hal harga dan kualitas. Harga sesuai dengan mutu menjadi pilihan diharapkan ada produk baru pelumas grease yang berspesifikasi food grade yang harganya

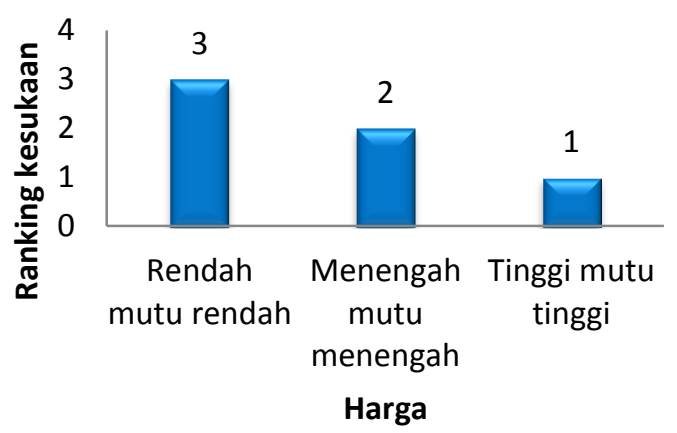

(b)

Keterangan: (a) ranking kesukaan harga pelumas grease oleh pedagang pelumas

(b) ranking kesukaan harga pelumas grease oleh pengguna pelumas

Gambar 7. Kesukaan harga food grade grease

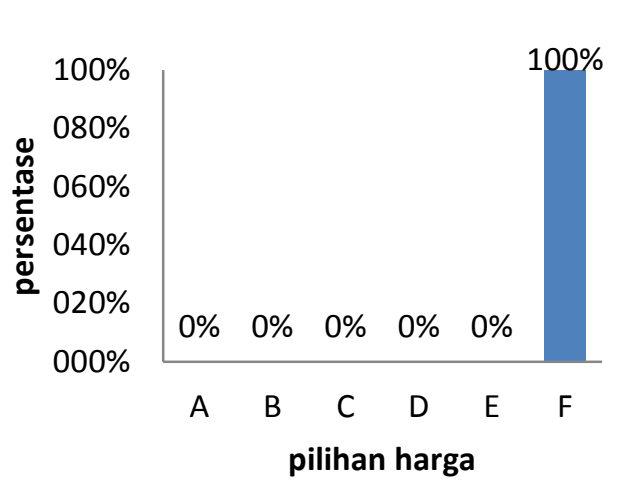

(a)

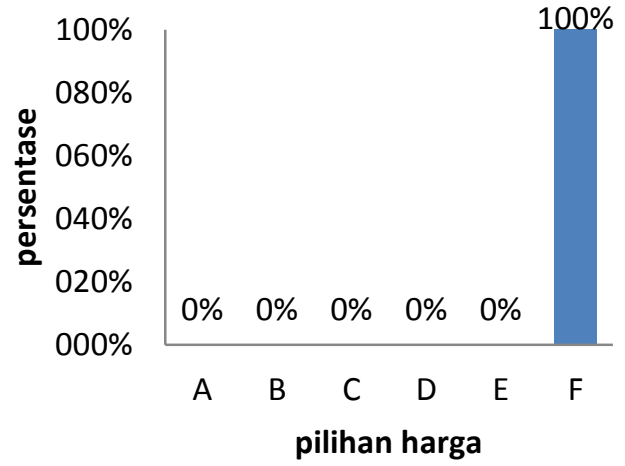

(b) 
Keterangan: (a) kesediaan harga maksimum untuk membeli pelumas grease oleh pedagang pelumas (b) kesediaan harga maksimum untuk membeli pelumas grease oleh pengguna Pelumas $\mathrm{A}=$ harga lebih $5 \mathrm{x}$ dari grease umum $\mathrm{B}=$ harga lebih $4 \mathrm{x}$ dari grease umum $\mathrm{C}=$ harga lebih $3 \mathrm{x}$ dari grease umum $\mathrm{D}=$ harga lebih $2 \mathrm{x}$ dari grease umum $\mathrm{E}=$ harga lebih 1,5 $\mathrm{x}$ dari grease umum $\mathrm{F}=$ harga lebih $1,25 \mathrm{x}$ dari grease umum

Gambar 8. Kesediaan membeli food grade grease

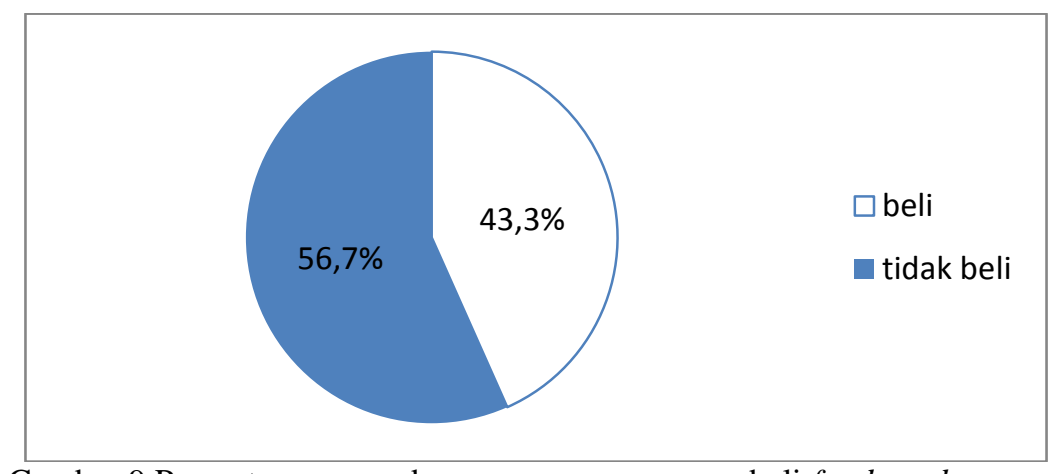

Gambar 9.Persentase responden pengguna yang membeli food grade grease

mampu bersaing dengan pelumas non food grade yang ada di pasaran. Pemilihan harga ini sesuai dengan pendapat Tellis (1986) yang menyatakan bahwa, produk baru dalam memasuki pasar baru menggunakan stratergi penetration price yaitu strategi dengan menetapkan harga rendah pada awal produksi, dengan tujuan dapat meraih pangsa pasar yang besar dan sekaligus menghalangi masuknya para pesaing. Harga rendah perusahaan dapat pula mengupayakan tercapainya skala ekonomi dan menurunnya biaya per-unit.Strategi ini mempunyai perspektif jangka panjang, dimana laba jangka pendek dikorbankan demi tercapainya keunggulan kompetitif yang berkelanjutan. Stratergi penetration price ditetapkan atas suatu produk baru dapat memberikan pengaruh yang baik bagi petumbuhan pasar dan mencegah timbulnya persaingan yang sengit (Tjiptono 2002).

Berdasarkan Gambar 8.diketahui bahwa kesediaan pengguna grease untuk membeli pelumas yang paling disukai yaitu dengan harga lebih 1,25 kali dari grease mesin umum. Harga disebut dipilih karena harga tersebut merupakan harga yang paling murah. Konsumen memilih harga yang paling murah untuk membeli pelumas food grade grease karena konsumen belum berani mengeluarkan uang yang lebih besar untuk membeli produk pelumas food grade grease yang masih merupakan produk baru.

Pelumas food grade grease merupakan produk baru yang harus bersaing dengan produk pelumas kompetitor. Oleh karena itu diperlukan penetapan harga yang tepat agar produk pelumas food grade grease mampu bersaing dengan kompetitor pelumas yang ada. Perusahaan agar dapat bersaing harus dapat menentukan harga dengan tepat. Harga tidak boleh terlalu rendah agar dapat menutup semua biaya yang dikeluarkan perusahaan dan memberikan keuntungan yang diinginkan, juga tidak boleh terlalu tinggi agar perusahaan dapat bersaing dengan para pesaingnya (Martusa dan Adie, 2011).

Merujuk pada Gambar 9.pengguna pelumas grease yang mau membeli pelumas food grade grease pada saat ditawarkan produk food grade grease sebanyak 43,3\%. Pengguna yang membeli pelumas food grade grease dikarenakan tertarik dan penasaran untuk mencoba menggunakan pelumas baru. Pelumas yang dibeli yang berukutran $150 \mathrm{~g}$ karena baru sekadar uji coba. Sedangkan, pengguna pelumas grease tidak banyak yang mau membeli pelumas food grade grease karena mereka belum percaya dengan pelumas ini sehingga menimbulkan kekawatiran jika menggunakan pelumas food grade grease akan 
merusak mesin mereka. Selain itu alasan mereka tidak membeli karena masih mempunyai stok pelumas yang belum dipakai.

\section{KESIMPULAN}

1. Spesifikasi pelumas yang disukai oleh pedagang grease yaitu pelumas spesifikasi food grade, sedangkan yang disukai oleh pengguna grease yaitu pelumas food grade dan pelumas mesin umum.

2. Warna pelumas food grade grease yang disukai oleh pedagang grease yaitu warna natural dan warna biru, sedangkan yang disukai oleh pengguna grease yaitu warna natural.

3. Ukuran kemasan food grade grease yang disukai oleh pedagang grease yaitu ukuran $350 \mathrm{~g}$ dan $150 \mathrm{~g}$ dengan kemasan cup dan curah, sedangkan pengguna grease menyukai ukuran $350 \mathrm{~g}$ kemasan cup.

4. Bentuk label pelumas food grade grease yang disukai oleh pedagang grease yaitu label bentuk bulat dengan warna merah dan hijau serta label bentuk persegi dengan warna merah, sedangkan yang disukai oleh pengguna grease yaitu label bentuk bulat dan persegi dengan warna merah.

5. Distribusi pelumas food grade grease yang disukai oleh pedagang grease yaitu toko grosir, toko eceran, bengkel dan pedagang keliling, sedangkan yang disukai oleh pengguna grease yaitu distribusi melalui toko grosir dan bengkel.

6. Promosi pelumas food grade grease yang disukai oleh pedagang grease yaitu melalui media internet, spanduk, brosur, radio dan poster, sedangkan pengguna grease menyukai promosi melalui media spanduk, brosur dan poster.

7. Harga pelumas food grade grease yang disukai oleh pedagang grease sama seperti yang disukai oleh pengguna grease yaitu harga rendah mutu rendah, harga menengah mutu menengah dan harga tinggi mutu tinggi.

\section{DAFTAR PUSTAKA}

Deswindi, L. 2007. Kecepatan Tingkat Penerimaan Konsumen dan Perilaku Konsumen Terhadap Produk Lama yang Mengalami Perubahan dan Produk
Inovasi Baru Dalam Upaya Memasuki Pasar dan Merebut Pasar. Business \& Management Journal Bunda Mulia 3 (2): 19-25.

Dewan Minyak Sawit Indonesia (DMSI), (2013), Diperkirakan Produksi CPO 2013 Mencapai 30 Juta Ton, http://www.sawit-centre.com, diakses pada tanggal 20 Maret 2013.

Direktorat Jenderal Perkebunan,(2012),Buku Statistik Perkebunan 2010-2012, Direktorat Jenderal Perkebunan, Jakarta.

Kupčinskas, A., R. Kreivaitis., J. Padgurskas., V. Makarevičienė. And M. Gumbytè. 2012. Modification of rapeseed oil and lard by monoglycerides and free fatty acids. JurnalMechanika 18 (1): 113-118.

Kotler, P. 1997. Manajemen Pemasaran; Analisis, Perencanaan, Implementasi dan Kontrol. Prenhallindo, Jakarta.

Kotler, P. dan G. Armstrong. 2008. PrinsipPrinsip Pemasaran. Erlangga, Jakarta.

Marimin dan H. Muspitawati. 2002. Kajian Strategi Peningkatan Kualitas Produk Industri Sayuran Segar (Studi Kasus Di Sebuah Agroindustri Sayuran Segar). Jurnal Teknologi dan Industrl Pangan 8 (3): 224-233.

Natadjaja, L. 2002. Pengaruh Komunikasi Visual Antar Budaya Terhadap Pemasaran Produk Pada Pasar Ekspor Ditinjau Dari Warna Dan Ilustrasi Desain Kemasan. JurnalNirmala. 4: 158168.

Tellis, G. J. 1986. Beyond the Many Faces of Price: An Integration of Pricing Strategies.Journal of Marketing 50 (4): 146-160.

Tjiptono, F. 2002. StrategiPemasaran. Penerbit ANDI, Yogyakarta.

Tri Yanto, Erminawati dan R. Naufalin.2009a. Uji Kinerja dan Preferensi Konsumen terhadap Food Grade GreaseBerbahan 
Tri Yanto dan Anis A. A. : Penentuan Strategi Bauran Pemasaran Pelumas ...

Dasar Minyak Sawit. Fakultas Pertanian Unsoed, Purwokerto.

Tri Yanto, R. Naufalin dan Erminawati. 2009b. Pengaruh Penambahan Antioksidan terhadap Karakteristik Pelumas Food Grade Grease dengan Bahan Dasar Minyak Sawit.Makalah Seminar Tahunan MAKSI.Bogor,25 November 200. MAKSI, Bogor.
Yuandana, Y. 2008. Penggunaan Media Billboard Dan Spanduk Sebagai Media Primer PT. Kawasan Industri JABABEKA Dalam Meningkatkan Penjualan Pada Tahun 2008.Skripsi. Universitas Mercu Buana. 